\title{
Factors affecting plagiarism among students at Jazan University
}

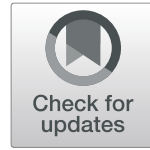

Hanaa A. Elshafei ${ }^{1,3^{*}}$ and Tamanna M. Jahangir ${ }^{2,3}$

\begin{abstract}
Background: Plagiarism has been described over the past decades as a multi-layer dishonesty phenomenon emerging in higher education. A number of research papers have described a host of factors such as gender, socialization, productivity benefit, study motivation, methodological uncertainty, or easy access to electronic information through the Internet and new technologies as the driving forces for plagiarism.

The effects of plagiarism are pervasive and no one is exempted. Neither unfamiliarity nor ignorance excludes a person from the compulsory plagiarism's ethical and legal problems. Institutional misconduct threatens student integrity, academic reputation, and professional reputation along with legal ramifications and financial penalties.

Methodology: The goal of the study is to investigate students' propensity to use the Internet to plagiarize, factors affecting their tendencies, and plagiarism reasons.

In this research, we analyze the perception of plagiarism and academic misconduct among students at Jazan University, study major dishonesty factors, and study students' views on plagiarism and misconduct laws.

Results: Examination of the responses of the students to various plagiarism situations showed misunderstandings and misconceptions about many forms of plagiarism.

Conclusion: Our study emphasizes that the problem in our society is that students or budding innovators are being pressured to get involved in academic dishonesty in order to perform better. To have a safe environment, the amount of academic misconduct, theft, and plagiarism must definitely be reduced to a minimum.
\end{abstract}

Keywords: Intellectual contribution, Academic misconduct, Plagiarism, Jazan University

\section{Introduction}

Plagiarism could be a major research concern of investigation within the academic world. It varies from the unreferenced use of published and unpublished ideas of others and from requests for research grants to the publication of a full paper under "new" authorship, sometimes in a different language. It can occur at any level of preparation, research, writing, or publishing: it refers to print and digital versions. In 2009, Koul et al. describes plagiarism as a form of cheating and stealing, when one person takes credit for the intellectual work of another in cases of plagiarism. According to Fishman (2009), plagiarism happens

\footnotetext{
* Correspondence: Prof_Elshafie@hotmail.com

1 Microbial Chemistry Department, National Research Centre, Cairo, Egypt

${ }^{3}$ Jazan University, Jazan, Kingdom of Saudi Arabia

Full list of author information is available at the end of the article
}

when someone does the following: (1) uses words, ideas, or work products; (2) credited to another person or source identifiable; (3) without attributing the work to the source from which it was obtained; (4) in a situation where there is a reasonable presumption of original authorship; and (5) in order to obtain any profit, credit, or gain that does not need to be financial. A considerable portion of the total number of genuine deviations from a great research hone is evaluated by Pecorari (2012).

While numerous organizations are inquiring about their definitions of literary theft, small work has been so far wiped out clarifying and legitimizing it (Gert and Stefan 2015). Nonetheless, there are many different opinions on how to interpret plagiarism and what makes theft of copyright inexcusable because it distorts rational credit. The word plagiarism is described, according to the Oxford English

\section{Springer Open}

๑ The Author(s). 2020 Open Access This article is licensed under a Creative Commons Attribution 4.0 International License, which permits use, sharing, adaptation, distribution and reproduction in any medium or format, as long as you give appropriate credit to the original author(s) and the source, provide a link to the Creative Commons licence, and indicate if changes were made. The images or other third party material in this article are included in the article's Creative Commons licence, unless indicated otherwise in a credit line to the material. If material is not included in the article's Creative Commons licence and your intended use is not permitted by statutory regulation or exceeds the permitted use, you will need to obtain permission directly from the copyright holder. To view a copy of this licence, visit http://creativecommons.org/licenses/by/4.0/. 
Dictionary online 2017, as the practice of taking the work or ideas of someone else and carrying them on as one's own.

This description, however, just gives some information about it and more detailed criteria are needed to make an act in a plagiarism case (Demirdover 2019). According to a study in the USA, there are five types of plagiarism that occur, direct, mosaic, self, paraphrase, and accidental, all focused on unethical issues:

1. Direct plagiarism: Without citing or pointing out the source, the entire text or part of the documents are copied word for word. This is one of the most common plagiarism types.

2. Mosaic plagiarism: The plagiarizer borrows phrases, without citation.

3. Self-plagiarism: The author uses his/her own earlier work without crediting it.

4. Paraphrasing/rephrasing: This is similar to direct plagiarism, except in this case the plagiarizer rearranges the words of the text or sometimes rephrases them according to their contents.

5. Accidental: Unintentional direct, mosaic, or paraphrase, without citation

Many of those teaching in higher education have considered plagiarism in the classroom as a form of dishonesty (Jereb et al. 2018). According to a report by plagiarism organization, "studies indicate that approximately 30 percent of all students may be plagiarizing on every written assignment they complete." Up to $55 \%$ of college presidents say plagiarism in students' papers has increased in the last decade. Plagiarism carries severe disciplinary and financial consequences. Repeated acts of plagiarism will lead to dismissal from the college.

The knowledge and skills of the student are threatened by academic misconduct; at the same time, it weakens the ability of the instructor to assess how well the student is performing in the course (Ryan et al. 2009). The principle is of supreme importance in all university programs, but it becomes particularly important in professional degree programs such as pharmacy, medicine, dentistry, and nursing as pass-outs (students) from such courses should have high ethics because their expectations impact human well-being directly (Neill 2008).

Regardless of the fact that plagiarism is carried out at all academic levels in this study, we focus on student misconduct and plagiarism, and why do students use the words or ideas of someone else and pass them on as their own? What factors are affecting this behavior?

\section{Material and methods}

The paper and pencil surveys are conducted during the academic year 2017-2018 at Jazan University in Saudi
Arabia. Students were informed verbally about the nature of the research and were invited to participate freely. This study was attended by a group of 381 students, 209 males (54.8\%) and 172 females (45.2\%). The ages of students range from 24 to 35 years.

\section{Instrument}

In this study, a simple questionnaire (both in English and Arabic) with a set of 10 questions was used to evaluate students' knowledge of plagiarism and examination misconduct. Initial questions were asked about their gender, age, area of study, field of specialization, and average time spent on the internet in the survey tool (questionnaire). Additional questions were asked.

To make it understandable to students, we have translated the questionnaire into Arabic and there is no room left for any confusing information. Participation was entirely voluntary, random, and anonymous. Most responding categories were yes/no/uncertain or disagree/agree/not sure. Hard copies of the survey tool were distributed among students from Jazan University's various colleges and were collected back in $10 \mathrm{~min}$.

\section{Results}

A total of 450 questionnaires were distributed, out of which 381 were returned and included in this study, with an overall response rate of $84.6 \%$ with $45.2 \%$ females and $54.8 \%$ males. Nevertheless, no unusual pattern has been found in the responses of male and female students. $81.5 \%$ of participants fell under the age group of 24-35. Approximately half (48\%) of the participants were students of pharmacy, $22 \%$ were students of dentistry, $20 \%$ were students of nursery, and $10 \%$ were students of science.

More than $55 \%$ of students were highly motivated to research and $45 \%$ fewer; $23.5 \%$ of students spend 2 or

Table 1 Frequency distribution of the variables affecting plagiarism among students at Jazan University

\begin{tabular}{llll}
\hline & & No. & Percent \\
\hline Gender & Male & 209 & 54.8 \\
& Female & 172 & 45.1 \\
& Missing & 69 & 15.3 \\
Area of study & Pharmacy & 183 & 48 \\
& Dentistry & 84 & 22 \\
& Nursing & 76 & 20 \\
& Science & 38 & 10 \\
Motivation for study & Lower & 171 & 45 \\
& Higher & 210 & 55 \\
Average time spent on internet in $\mathrm{h}$ & 2 or less h & 90 & 23.5 \\
& Between 2 and 5 h & 139 & 36.5 \\
& 5 or more $\mathrm{h}$ & 152 & 40 \\
\hline
\end{tabular}


less hours per day on the Internet, $36.5 \%$ spend 2 to $5 \mathrm{~h}$ on the Internet, and $40 \%$ spend 5 or more hours per day on the Internet. The general information can be seen in Table 1.

$50.6 \%$ of participants agree that to complete their tasks and notice, they use the Internet. $40.15 \%$ of respondents accepted that this was due to social pressure caused by academic misconduct. Approximately $40 \%$ use plagiarism as their last resort fairly frequently. $56.9 \%$ of students strongly agreed to have strict enforcement of laws against such misconduct. However, only $32.5 \%$ said academic dishonesty is ok until caught. To our surprise $62.7 \%$ had no knowledge of punishments for plagiarism and academic misconduct.
Only $24.7 \%$ admitted that they knew people who were intentionally involved in plagiarism, and $52 \%$ of students supported the idea of implementing strict rules to help future generations (Fig. 1).

\section{Discussion}

The idea of plagiarism and academic misconduct has become so popular in the current world of competition (Bradshaw and Lowenstein 1990). Interventions aimed at curbing plagiarism do not always overpower the incentive of individuals to steal, and corruption cannot be minimized. In 2006, Scanlan reported that student academic misconduct for colleges and universities, including those responsible for preparing health professionals, is a growing problem. While the introduction of honor

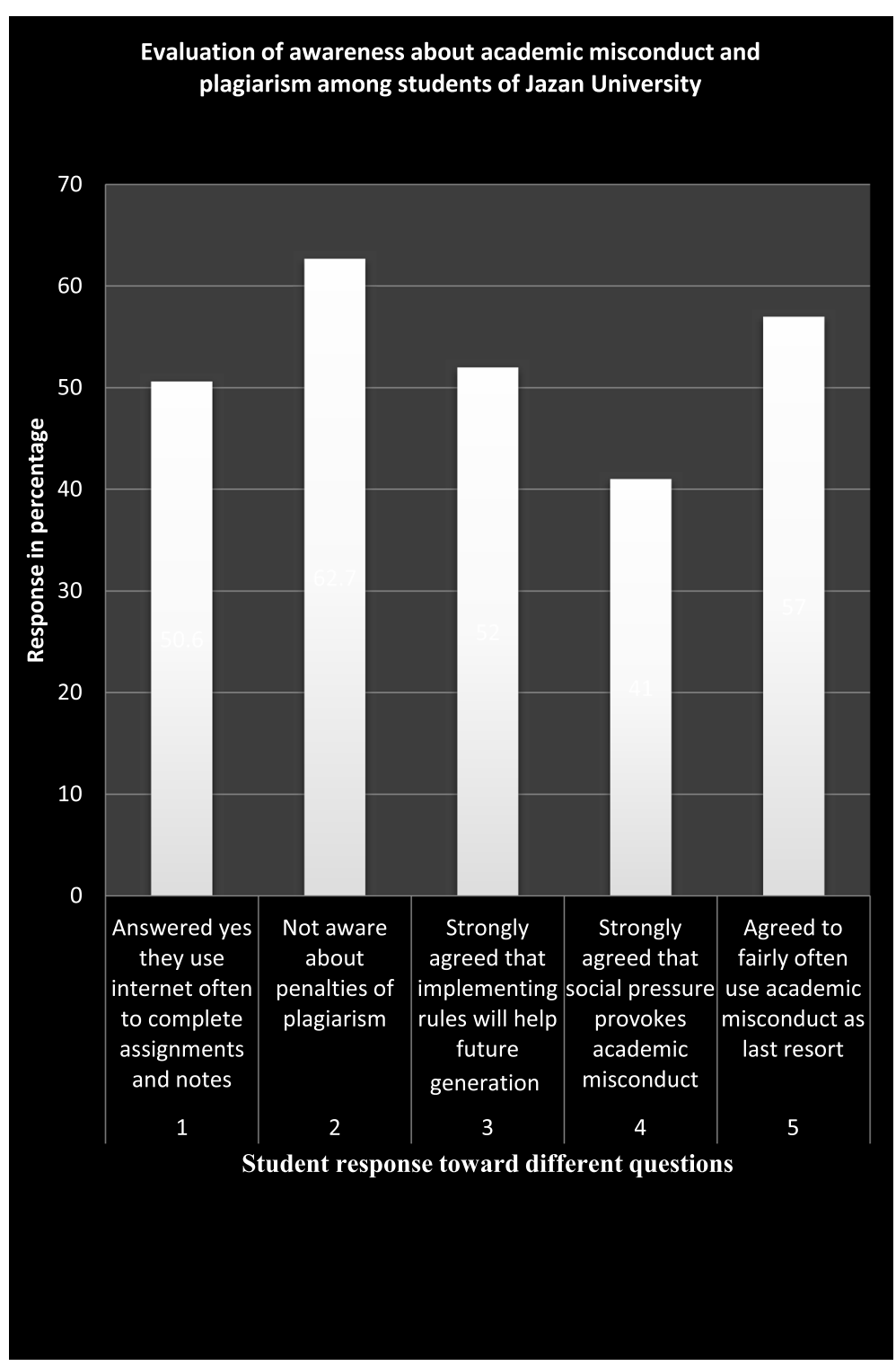

Fig. 1 The results of the survey in terms of percentage of response among students of Jazan University 
codes has had a positive impact on this issue, further reduction in student cheating and plagiarism can only be accomplished through a comprehensive strategy that supports an academic integrity organizational culture. A questionnaire was issued to postgraduate students from Sweden's medical faculties who attended a research ethics course during the 2008/2009 academic year and 58\% replied. Less than one third of the respondents wrote that in the previous 12 months they had heard of scientific dishonesty (Nilstun et al. 2010). Therefore, it becomes our moral as well as ethical duty to make our students aware of the harms caused by such actions and we must also inform them about the consequences for academic misconduct that are approved by law.

Our main objective should be to provide our students with quality education and knowledge as well as good qualifications in examinations and research, but not at the expense of our integrity and dignity, which is called into question in the course of plagiarism and other academic dishonesty. Examination of the responses of Jazan University students to various plagiarism situations showed misunderstandings and misconceptions about many forms of plagiarism.

Our study emphasizes that in our society, the problem is that it pressures students or budding innovators to get involved in academic dishonesty to perform better.

Not only will it help to follow the rules, but we also need to prepare our students to withstand failure. Not only at school, but also at home, a healthy atmosphere should be given so that our students can perform without any fear of failure (Ryan 2009). The amount of academic misconduct, stealing, plagiarism should certainly be reduced to a minimum. To avoid and keep a check on plagiarism, we recommend proper education and technology involvement. This should serve as a wakeup call to transnational higher education regarding plagiarism (Palmer et al. 2019).

\section{Conclusion}

The key results of this research paper indicate that new technologies and the Internet have a clear and important impact on plagiarism. Since most students in our study agree that new technologies and the Web have a strong influence on plagiarism, we may conclude that technological advances and globalization have started to break down national borders and cross cultural boundaries.

In addition, the results could be a starting point for more research into the impact of digitalization and the Internet on plagiarism, and the role of socialization in plagiarism, may contribute to the plagiarism debate in institutions of higher education.

The variables found to be of the greatest importance by the students as causes of plagiarism relate to time management issues and social pressure, in addition to the lack of clarity and incomplete policies that regulate plagiarization.

Existing documents, procedures, and regulations do not explicitly describe the disciplinary mechanisms for plagiarizing students. Understanding the reasons behind plagiarism and promoting understanding among students of the problem may help prevent future academic misconduct through improved support and guidance during the time students study at the university. In the near future, focusing on preventive measures could have a positive impact on good scientific practice.

\section{Acknowledgements}

All participants and academic staff who helped us in conducting this survey. Thanks and appreciations for time and effort in answering our questionnaires to gether and to provide needed data.

\section{Authors' contributions}

HA participated in distributing and collecting questionnaires and monitoring data and prepared the table. $T$ analyzed and interpreted the data and prepared the figure. Both authors contributed in writing the manuscript. Both authors read and approved the final manuscript.

\section{Authors' information}

Applicable

Funding

Not applicable

\section{Availability of data and materials}

The datasets used and analyzed during the current study are available from the corresponding author on reasonable request.

\section{Competing interest}

No conflict of interest exists.

Ethics approval and consent to participate Not applicable

\section{Consent for publication}

The authors of this manuscript have read the final version of this article and have agreed to its publication.

\section{Author details}

${ }^{1}$ Microbial Chemistry Department, National Research Centre, Cairo, Egypt. ${ }^{2}$ Leslie Groves Hospital, Helensburgh road, Dunedin, NZ, New Zealand. ${ }^{3}$ Jazan University, Jazan, Kingdom of Saudi Arabia.

Received: 14 January 2020 Accepted: 2 April 2020

Published online: 07 May 2020

\section{References}

Bradshaw MJ, Lowenstein AJ (1990) Perspectives on academic dishonesty. Nurse Educ 15(5):10-15

Demirdover C (2019) Plagiarism. Turkish Journal of Plastic Surgery 27(1):1.

Fishman T (2009) We know it when we see it is not good enough: toward a standard definition of plagiarism that transcends theft, fraud, and copyright. Paper presented at the 4th Asia Pacific Conference on Educational Integrity, NSW, (4APCEI) :1-5.

Gert H, Stefan E (2015) Plagiarism in research. Medicine,Health Care and Phisiology 18(1):91-101.

Jereb E, Perc M, Lämmlein B, Jerebic J, Urh M, Podbregar I (2018) Factors influencing plagiarism in higher education: a comparison of German and Slovene students. PLoS One 13(8):e0202252

Koul R, Clariana RB, Jitgarun K, Songsriwittaya A (2009) The influence of achievement goal orientation on plagiarism. Learn Indi Diff 19:506-512

Neill US (2008) Publish or perish, but at what cost? J Clin Invest 118(7):2368 
Nilstun T, Löfmark R, Lundqvist A (2010) Scientific dishonesty-questionnaire to doctoral students in Sweden. J Med Ethics 36(5):315-318

Palmer A, Pegrum M, Oakley G (2019) A wake-up call? Issues with plagiarism in transnational higher education. Ethics Behav 29(1):23-50

Pecorari D (2012) Textual plagiarism: how should it be regarded? Office of Research Integrity Newsletter 20 (3):3-10.

Ryan G, Bonanno H, Krass I, Scouller K, Smith L (2009) Undergraduate and postgraduate pharmacy students' perceptions of plagiarism and academic honesty. Am J Pharm Educ 73(6):105

Scanlan CL (2006) Strategies to promote a climate of academic integrity and minimize student cheating and plagiarism. J Allied Health 35(3):179-185

\section{Publisher's Note}

Springer Nature remains neutral with regard to jurisdictional claims in published maps and institutional affiliations.

\section{Submit your manuscript to a SpringerOpen ${ }^{\circ}$ journal and benefit from:}

- Convenient online submission

- Rigorous peer review

- Open access: articles freely available online

- High visibility within the field

- Retaining the copyright to your article

Submit your next manuscript at $\boldsymbol{\nabla}$ springeropen.com 